\title{
FUZZY MULTI-CRITERIA DECISION MAKING MODEL FOR SUBCONTRACTOR SELECTION IN INTERNATIONAL CONSTRUCTION PROJECTS
}

\author{
Serdar ULUBEYLI ${ }^{\mathrm{a}}$, Aynur KAZAZ ${ }^{\mathrm{b}}$ \\ ${ }^{a}$ Department of Civil Engineering, Faculty of Engineering, Bulent Ecevit University, \\ 67100 Zonguldak, Turkey \\ ${ }^{b}$ Department of Civil Engineering, Faculty of Engineering, Akdeniz University, \\ 07058 Antalya, Turkey
}

Received 18 October 2012; accepted 25 August 2013

\begin{abstract}
A general contractor's ability to select proper subcontractors in foreign projects is a key competitive advantage. Toward this aim, a subcontractor selection model (CoSMo) was developed in this study. As a computational approach, the fuzzy sets method was employed because it can model human judgment by means of linguistic values, combining qualitative and quantitative decision criteria into an aggregate measure. Although the algorithm may be complex for easy acceptance by industrial practitioners, this disadvantage was minimized through a computer-supported system. In order to gain a better understanding of the current practice of CoSMo, a real world construction project was conducted. As a result, it was observed that CoSMo has high practical application and can be used as an advisory system by satisfying principal contractor's requirements to reduce the risk involved in the selection of a subcontractor. Moreover, it gives an initial idea of how subcontractors perform on each decision criterion and allows the main contractor to understand the picture on the strong and weak points of each bidder and thereby to take conscious decisions.
\end{abstract}

Keywords: subcontractor selection, fuzzy sets, multiple criteria decision making, international construction projects.

JEL Classification: D81, L24, L74, M15, M16, M51.

\section{Introduction}

The subcontracting system is usually described as the contractual process in which a principal contractor subcontracts some parts of the work to another contractor (Chiang 2009; Lingard et al. 2010). In the construction industry, many general contractors act as project agents, and transfer actual project tasks to subcontractors for execution (Shash 1998; Grasso et al.

Corresponding author Serdar Ulubeyl

E-mail: serdar.ulubeyli@karaelmas.edu.tr 
2008; Ng, Tang 2010). Subcontractors may supply workers, materials, equipment, tools, and even design (Tam et al. 2011). They could bring unique skills and talents for specialized work such as steel work, concreting, installation, and other sophisticated facility systems (Hinze, Tracey 1994). Since a huge proportion of work is conducted by subcontractors, the non-performance of any subcontracting organization is one of the main causes for project failure (Arditi, Chotibhongs 2005; De Silva et al. 2012).

Improvements in subcontractor selection processes have not received the attention that one would expect from a significant contribution to the construction industry. A construction project which lacks a rigorous subcontractor selection process is prone to many serious problems such as time and cost overruns, substandard works, disputes, and finally dissatisfaction of clients. From another perspective, it may also lead to the resignation of qualified subcontractors from the business or result in a lowering of their standards; thus producing cheap and poor-quality work (Choudhry et al. 2012; Kazaz et al. 2012).

\section{Previous researches}

Although numerous researches on the prequalification process of main contractors have been carried out to date (Nguyen 1985; Juang et al. 1987; Paek et al. 1992; Elton et al. 1994; Singh, Tiong 2005; Brauers et al. 2008; Mitkus, Trinkuniene 2008; Turskis 2008; Zavadskas et al. 2008, 2009, 2010; Plebankiewicz 2009, 2010; Podvezko et al. 2010; Arslan 2012; Cheng, Kang 2012; San Cristobal 2012; Vahdani et al. 2013; Wang et al. 2013), only a number of scientific papers discussing the problem of construction subcontractor prequalification have been published. $\mathrm{Ng}$ and Luu (2008) developed a case-based system for construction subcontractor registration. Mbachu (2008) suggested a framework for use by main contractors and consultants in the assessment of the suitability and performance of subcontractors. Arslan et al. (2008) proposed a web-based subcontractor evaluation system. Ip et al. (2004) made a specific research on subcontractor selection in a construction project, employing a mathematical model developed for a specific use in the manufacturing industry and based on cost and duration. Tserng and Lin (2002) developed an Internet-based model in order to take proposals from subcontractors. They take into account risk and profitability as well as reciprocal variations between these two factors by means of cost and time schedules. Kumaraswamy and Matthews (2000) suggested a system based on partnering relationships for the choice of subcontractors. They investigated the effect level of project-based or long-term partnership on the selection. In their study, a general framework was created without developing a specific model. Okoroh and Torrance (1999) proposed a model for subcontractor selection in refurbishment projects. They have presented a model for analyzing the subcontractor's risk elements in construction refurbishment projects and described a prototype knowledge-based expert system. Albino and Garavelli (1998) used neural networks for the selection of subcontractors. However, these studies have some drawbacks which can be listed in the following items:

- Ip et al. (2004), Tserng and Lin (2002), Okoroh and Torrance (1999), and Albino and Garavelli (1998) considered very few selection criteria and formed one-tier selection procedure, which made the selection process superficial, 
- Ip et al. (2004) and Tserng and Lin (2002) did not take into account qualitative criteria, which was obviously in contradiction with the characteristics of a real life problem,

- Ng and Luu (2008), Okoroh and Torrance (1999), and Albino and Garavelli (1998) depended solely on past data that should be collected and trained to solve the problem, which produced a time-consuming model in the short- and mid-term,

- Mbachu (2008) and Ip et al. (2004) did not employ any automated system, which made the calculation procedure an effort-consuming process,

- Okoroh and Torrance (1999) has project-specific criteria, which did not allow the model to be easily used for all kinds of projects, and

- Arslan et al. (2008) evaluated criteria that were scored on a 1 to 10 scale, which was, in fact, not adequately suitable for decision makers because of the fact that human perception and judgment cannot be quantified precisely and that decision makers intuitively feel more comfortable providing their judgments in verbal terms (rather than numerically), which, due to subjectivity, leads to ambiguity in human decision making (Poyhonen et al. 1997).

\section{Objectives of the study}

This study intends to develop a construction subcontractor selection model, called CoSMo, by taking into account the above-mentioned shortcomings of previous researches.

Although CoSMo can be employed in domestic construction projects, it was developed especially for international projects. This is mainly because principal contractors and subcontractors in domestic projects mostly have accumulated experience of working together on previous (and potantially on future) projects. Since main contractors know features and performances of many domestic subcontractors, they usually prefer working with the same subcontractors. However, this is not the case in international projects where the shared experience is less common and main contractors often have to work with unknown subcontractors from host countries or totally different third countries. Past relationships between the parties can be the unique factor in selecting subcontractors in domestic projects, whereas this can hardly be implemented in international projects especially where main contractor has not undertaken any project in the host country or city before.

In this context, main contractors need a sound evaluation tool to gain knowledge-based competition capabilities in the international construction market while choosing subcontractors. In practice, a few decision makers in main contracting firms choose subcontractors based on solely cost or a few criteria without employing any evaluation method. The last decision is often made by top managers based on heuristic techniques combining experience, intuition, and subjective judgment (Ulubeyli et al. 2010). It means that subcontractor selection decisions are generally a 'gut feel' issue. Of course, the same organization can perform differently even under very similar conditions. However, many contractors have not developed their well-structured, systematic, and formalized process to prequalify subcontractors, and thus subcontracting selection process often lacks reliable standards. In this type of tender evaluation, there also appears to be a lack of a realistic working models capable of simultaneously 
(i) managing a large number of criteria and the complex selection process, (ii) compiling inputs for multiple decision-criteria, (iii) reducing the complexity of data handling, (iv) offering computer interaction that makes a model highly flexible to any change in situation and that facilitates the implementation of the fuzzy sets approach, (v) storing and reporting all input data, (vi) coping with multi-criteria information, which is imprecise and subjective, and accommodating non-numerical measures by means of fuzzy reasoning, (vii) giving an initial idea of how subcontractors perform on each decision criterion and allowing the main contractor to understand the picture on the strong and weak points of each bidder, (viii) requiring only one user, who may not be a construction practitioner, to run the model, (ix) creating a database system for shorter and easier evaluation of future subcontract packages by a feedback mechanism, and lastly $(\mathrm{x})$ having high practical application. The model developed in this study gather all these characteristics together.

Moreover, proactive subcontractors who seek added knowledge about a main contractor's decision process can use CoSMo as an effective evaluation tool by focusing on the factors that are perceived to be important to main contractors and by examining their chances of success to qualify. An understanding of the main contractor's decision making behavior during the selection process can equip the subcontractor with the edge required to overcome competitors, or at least to improve their chances of doing so by increasing their chances of being awarded the sublet work. In brief, CoSMo can motivate the subcontractors continuously to concentrate on improving characteristics that are of interest to main contractors.

As a result, CoSMo can be used as a main contractor advisory system in choosing subcontractors by satisfying main contractor's needs to reduce the risk involved in the selection of a subcontractor, to remove subcontractor-based problems during construction, and finally to complete a construction project successfully (Ulubeyli 2008).

\section{Fuzzy multi-criteria decision making}

In the present study, the fuzzy sets theory was employed as a solution methodology. This has several reasons which are explained in a detailed manner below.

During the conventional evaluation process of a decision-making problem, individuals are often required to give exact or precise numerical assessments with regard to each decision criterion. Although this is achievable, the quantitative representation of subjective characteristics may impose a heavy burden on the decision maker. Furthermore, scoring in these numbers may not "truly" reflect the decision maker's preferences. Humans are not machines, so they are susceptible to intuitive judgments based on individual knowledge and experience within domain. Therefore, scoring in linguistic terms is the closest form of representing human judgment, and decision makers may wish to evaluate criteria by using linguistic expressions or variables, which facilitates the processing of raw data that is normally difficult to represent. It is desirable that decision makers not be forced to provide exact numerical assessments, but rather, should be free to express their judgments subjectively. The fuzzy sets method introduced by Zadeh (1965) facilitates this, since asking preferences directly by crisp values for weighting and rating does not sufficiently accurately represent individual semantic cognition status. Linguistic values are used to 
address the vagueness of human thoughts in the selection process. Fuzzy logic is a very powerful tool that can be used to quantify imprecise data, and has the advantage of mathematically represent uncertainty and vagueness. As a conclusion, since knowledge can be expressed in a more natural way by using fuzzy sets, many engineering and decision problems can be greatly simplified. One of the most salient features of fuzzy logic is that subjective information that is available only as a linguistic statement can easily be made quantitative. The fuzzy inference can also model human judgment by combining qualitative and quantitative decision criteria into an aggregate measure.

Therefore, an ideal decision support system for subcontractor prequalification should have the ability of handling both quantitative and qualitative data, such that rational and consistent decisions can be made. However, incorporating capability measures of subcontractors into bid evaluation is no easy task. The measurements of qualitative factors can be described as "an art where subjective judgment, based on an individual's experience, becomes an essential part of the process". The information for these factors is qualitative in nature, and the assessment and interpretation for such require expert predictive judgment. Typically, it is necessary to transform the qualitative and quantitative subcontractor's information into objective numerical figures via a co-existent treatment. In the modeling process, linguistic values of selection criteria and evaluation of these criteria for each alternative are converted to the quantitative format by means of fuzzy sets. This helps decision-makers express linguistic value for criteria. The use of the linguistic values can be justified by the fact that human decision making involves ambiguity, vagueness, uncertainty, and imprecision. Although it may be too complex for easy acceptance by industry, this disadvantage was minimized via a computer-supported system in this study. In addition, fuzzy sets theory as a selection methodology shows an evidence of academic usage (Holt 1998).

\section{Fuzzy algorithm of CoSMo}

Many simple decision processes are based on a single criterion. Often, however, decisions should be made in an environment where more than one criterion governs constraints on the problem, and the value of each of these criteria is different (Lashgari et al. 2012; Yu 2013).

Two primary issues in multi-criteria decision making are to acquire meaningful information regarding the satisfaction of the criteria by the various choices or alternatives and to rank or weight the importance of each of the criteria. The approach illustrated below defines a decision calculus that requires only "ordinal" information on the ranking of preferences and importance weights (Yager 1981).

The typical multi-criteria decision problem involves the selection of one alternative, $a_{\mathrm{i}}$, from a universe of alternatives $A$ given a set, $C$, of criteria that are important to the decision maker. Decision maker want to evaluate how well each choice satisfies each criterion, and he/ she wish to combine the weighted criteria into an overall decision function in some plausible way. This decision function essentially represents a mapping of the alternatives in $A$ to an ordinal set of ranks. This process naturally requires subjective information from the decision authority concerning the importance weight of each criterion. Ordinal orderings of these importance weights are usually the easiest to obtain. Numerical values, ratios, and intervals 
expressing the importance weight of each criterion are difficult to extract and, if attempted and then subsequently altered, can often lead to results inconsistent with the intuition of the decision maker. To develop this calculus some definitions are required. Define a universe of $n$ alternatives, $A=\left\{a_{1}, a_{2}, \cdots, a_{n}\right\}$ and a set of $r$ criteria, $C=\left\{C_{1}, C_{2}, \cdots, C_{r}\right\}$. Let $C_{i}$ indicate the $i$ th criterion. Then the degree of membership of alternative $a$ in $C_{i}$, denoted $\mu_{C_{i}}(a)$ is the degree to which alternative $a$ satisfies the criteria. A decision function that simultaneously satisfies all of the decision criteria is sought; hence, the decision function, $D$, is given by the intersection of all criteria: $D=C_{1} \cap C_{2} \cap \cdots \cap C_{r}$. Therefore, the grade of membership that the decision function, $D$, has for each alternative $a$ is given by:

$$
\mu_{D}(a)=\min \left[\mu_{C_{1}}(a), \mu_{C_{2}}(a), \cdots, \mu_{C_{r}}(a)\right] .
$$

The optimum decision, $a^{*}$, will then be made by the decision maker according to the ranking of alternatives in a decreasing order. Let now define a set of preferences, $\{P\}$, which will be constrained to being linear and ordinal. According to Ross (1997), elements of this preference set can be linguistic values such as none, low, medium, high, absolute, or perfect; or they could be values on the interval $[0,1]$; or they could be values on any other linearly ordered scale, e.g., $[-1,1],[1,10],[20,90]$ etc. These preferences will be attached to each of the criteria to quantify the decision maker's feelings about the importance that each criterion should have. Let the parameter, $b_{i}$, be contained on the set of preferences, $\{P\}$, where $i=1,2, \cdots, r$. Hence, the decision maker has for each criterion a measure of how important it is to him/her for a given decision. The decision function, $D$, now takes on a more general form when each criterion is associated with a weight expressing its importance to the decision maker. This function is represented as the intersection of $r$-tuples, denoted as a decision measure, $M\left(C_{i}, b_{i}\right)$, involving criteria and preferences,

$$
D=M\left(C_{1}, b_{1}\right) \cap M\left(C_{2}, b_{2}\right) \cap \cdots \cap M\left(C_{r}, b_{r}\right) .
$$

A key question is what operation should relate each criterion, $C_{i}$, and its importance weight, $b_{i}$, that preserves the linear ordering required of the preference set, and at the same time relates the two quantities in a logical way where negation is also accommodated. The classical implication operator $(\rightarrow)$ satisfies these requirements. In this implication, the proposition $b_{i}$ is referred to as the hypothesis and the proposition $C_{i}$ is referred to as the conclusion (Zadeh 1973). In fact, the relation enables each decision measure, denoted as $M\left(C_{i}, b_{i}\right)$ in Equation (2), to be calculated mathematically. Hence, the decision measure can be replaced with the classical implication by means of the implication's classical equivalent where $\overline{b_{i}}$ is the complement of $b_{i}$,

$$
M\left(C_{i}, b_{i}\right)=b_{i} \rightarrow C_{i}=\overline{b_{i}} \cup C_{i}
$$

Justification of the implication as an appropriate measure can be developed using an intuitive argument. The statement " $b_{i}$ implies $C_{i}$ " indicates a unique relationship between a preference and its associated criterion. Whereas various criteria can have the same preference weighting in a cardinal sense, they will be unique in an ordinal sense even though the equality 
situation $b_{i}=b_{j}$ for $i \neq j$ can exist for some criteria. Ordering will be preserved because $b_{i} \geq b_{j}$ will contain the equality case as a subset. Therefore, a reasonable decision model will be the joint intersection of $r$ decision measures:

$$
D=\bigcap_{i=1}^{r}\left(\bar{b}_{i} \cup C_{i}\right),
$$

and the optimum solution, $a^{*}$, will be decided by the decision maker according to the concluding ranking of alternatives. In fact, equation (4) denotes that the model essentially accepts the "weakest link" approach as suggested by Smithson and Verkuilen (2006). This means that a chain is only as strong as its weakest link and the minimum $(\cap)$ strength of all the links in the chain governs the strength of the overall chain (Ragin 2000).

This model is intuitive in the following manner. As the $i$ th criterion becomes more important in the final decision, $b_{i}$ increases, causing $\bar{b}_{i}$ to decrease, where now $C_{i}(a)$ will be the value of the decision function, $D$, representing alternative $a$. Since the type of input and output data is group membership, each alternative is ranked in order according to their membership value. As was used in the utility model for comparing fuzzy numbers developed by Juang et al. (1987), a subcontractor prequalification ranking index ranging from 0.1 to 0.9 is obtained; the higher the index, the greater the perceived capability of the subcontractor. From another perspective, as explained in the above algorithm, membership values of preference set $\left[\mu_{b_{i}}(a)\right]$ and alternatives' set for each criterion $\left[\mu_{C_{i}}(a)\right]$ should be determined by decision-maker. It is more suitable that decision-maker expresses his/ her judgment on these values by linguistic variables rather than specific numerical values. Determining the number of conversion scales which are applied to transform linguistic terms into fuzzy numbers is generally intuitive (Chen, Hwang 1992). Miller (1965) noted that the scale of "seven plus or minus two" generates the largest amount of information from a decision-maker regarding the objectives on the basis of absolute judgments. In this study, an interval scale of nine was adopted. The choice of nine rating levels of performance is appropriate because more or fewer categories appear to be either too many or too few for user friendliness and accuracy of evaluation. As shown in Figure 1, nine linguistic values were used for determining numerical rating values of these variables. Similarly, nine linguistic weight values are illustrated in Figure 2.

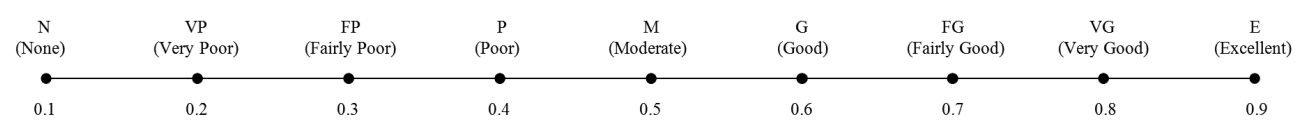

Fig. 1. Linguistic rating terms

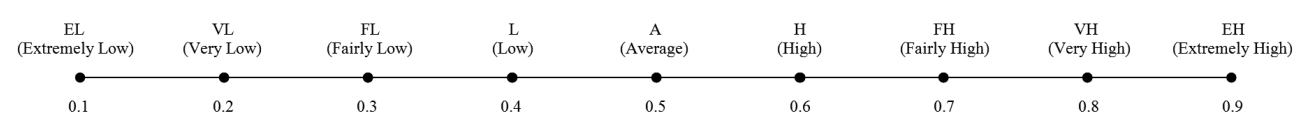

Fig. 2. Linguistic weighting terms 
A more detailed explanation of the value of this approach should be given. For a particular criterion, the negation of its preference acts as a barrier such that all ratings of alternatives below that barrier become equal to the value of that barrier. Here, all distinctions less than the barrier are disregarded while keeping distinctions above this barrier. However, in the decision model developed here, this barrier varies, depending upon the preference of the criterion to the decision maker. The more important is the criterion, the lower is the barrier, and thus the more levels of distinction there are. As a criterion becomes less important, the distinction barrier increases, which lessens the penalty to the criterion. In the limit, if the criterion becomes totally unimportant, then the barrier is raised to its highest level and all alternatives are given the same weight and no distinction is made. Conversely, if the criterion becomes the most important, all distinctions remain. In sum, the more important a criterion is in the decision process, the more significant its effect on the decision function, $D$ (Yager 1981; Ross 1997).

\section{The structure of CoSMo}

Decision support systems can be defined as "computer-aided systems designed to assist decision-makers to make better, faster, and/or cheaper decisions". They organize evaluation processes and help to make the processes less sophisticated, less time- and effort-consuming, more efficient in analyzing tender-data, and easier to execute. These systems facilitate computations through computer-supported models and ensure that the models are put into practice especially where the complicated algorithms and calculations such as fuzzy sets are in use.

In order to efficiently program and run CoSMo, the computational system was created using Visual Basic for Application (VBA) and MS Access, which are Windows-standard computing softwares. The platform of Windows XP was adopted for developing CoSMo as the programming application has the advantage of good capacity for model programming and database management. It is also an important advantage that CoSMo occupies only a space of 30-32 megabytes in the hard disc, together with recorded data. The release package for the system was designed so that it can be easily installed to a Windows system and can run independently without the need for additional configurations. CoSMo can also be used in computers where Microsoft Office has not been set up. The most important advantage of employing VBA and MS Access is their familiarity for most users. VBA was used to code the detailed processes of CoSMo, to automatically handle tasks, to render a high interface, and to offer friendly interaction with users. "If ... Then ... Else" type codes were produced in the VBA environment. In other words, the database's interface was designed with VBA to make easier the interaction between CoSMo and users, hiding the calculations and operations from the user's eyes. MS Access was selected in the present research effort, because it is a good storing and reporting tool. It also applies to VBA codes as modules, and user forms and reports supported by these modules work as menus that execute the proposal evaluation process. The main menu that shows and manages the modules of this program is illustrated in Figure 3. 


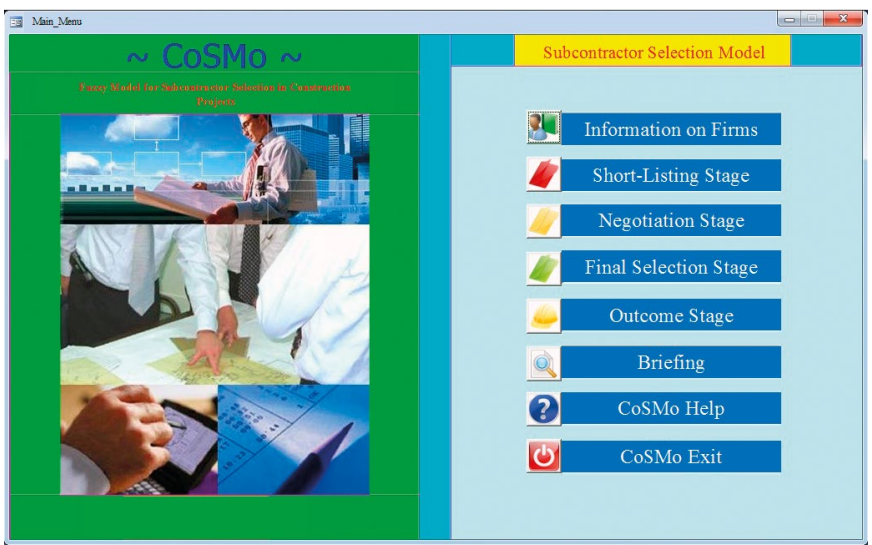

Fig. 3. Main menu of CoSMo

The entire algorithm presented in Section 5 is repeated in the same way in all phases of CoSMo, i.e., "short-listing", "negotiation", "final selection", and "outcome", to reach final values. In using CoSMo, a main contractor needs to collect information from bidding subcontractors in referring to the parameters. After inputting the information into CoSMo, the system allows each subcontractor's final value to be calculated. In other words, after allocating rating and weight values for criteria of "short-listing", "negotiation", and "final selection", three intermediate values are obtained for each alternative. In the "outcome" step, these three values are automatically included as ratings of previous three stages. Then, weight values of them are assessed by decision maker(s) and final values are calculated.

\section{Procedures in the subcontractor selection process}

As demonstrated in Figure 4, the forms "short-listing", "negotiation", "final selection", and "outcome", which are perceived as separate objects by the program, operate as data input modules, while the "briefing" report runs as the resultant output module. Consequently, it was intended in this study to develop specific modules with a special focus on subcontractor selection for international projects, where the evaluation parameters are more in number and complexity due to availability of mostly unknown bidders, and therefore decision support is even more valuable.

In general, all prequalification systems have the same basic steps: develop the criteria, gather the related data, apply the data to criteria, and decide whether to prequalify or remove the candidate. This procedure was also met by CoSMo using a three-step decision hierarchy. This three-stage process including "short-listing", "negotiation", and "final selection", ensures that subcontract packages do not reflect unwarranted variations in likely performance of subcontractors. Toward this aim, subcontractors must qualify for each stage. The decision maker introduces a cut-off point for prequalification as follows: the subcontractors whose membership values equals lower than "moderate" for "the sum of short-listing" is not considered for the negotiation and final selection stages. Namely, short-listing scores below this 


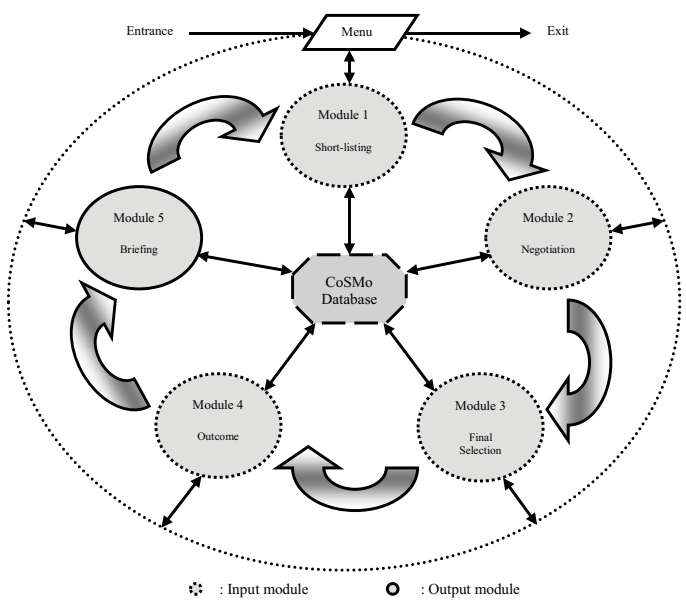

Fig. 4. Operating mechanism of CoSMo

pre-determined threshold are deemed non-responsive. This frontier acts as a fixed limit from which all subcontractors can be compared, and serves as a measure of the quality of subcontractors vying for the project. The baseline is also believed to reflect the industry's standard in general. In practice, however, it is possible that no one passes the threshold. In such a case, main contractor may review his selection strategy and reduce the current standard.

Figure 5 shows the application hierarchy of the first stage, i.e., "short-listing". First, an in-house committee in the name of the main contracting company invites subcontractors for preliminary negotiation and requests their formal documents concerning past experience, past performance, financial strength, workload, safety record, litigation history, and location of home office to evaluate them and assign corresponding ratings. In the document about past performance, randomly-selected some information may be checked by communicating with the related past main contractors. Formal relationship, personal relationship, and reputation are the other criteria to be considered in this stage. Ratings of formal relationship and personal relationship are determined according to the preliminary negotiation while those of reputation are assigned after controlling reputable past projects undertaken by applicants. After compiling all of the information about these ten criteria, the committee makes a meeting to determine rating scores and project-specific weights of them. It is suggested that decisions on these values are taken by consensus rather than by majority. The required explanations on these criteria should be added to CoSMo to store for using in future evaluations. The fuzzy algorithm is then applied automatically and, as mentioned above, those who have scores greater than a pre-determined threshold qualify. These bidders are sent detailed tender documents and project drawings to give their cost- and time-based proposals.

Figure 6 illustrates the selection process followed in the second and third stages, i.e., "negotiation" and "final selection". Here, a detailed negotiation is held between the committee and subcontractors who have passed the first stage. Under the "negotiation" stage, the committee tests subcontractors on seven criteria such as knowledge of project, reliability, selfless attitudes, ability to solve problems, enthusiasm for the project, quality 


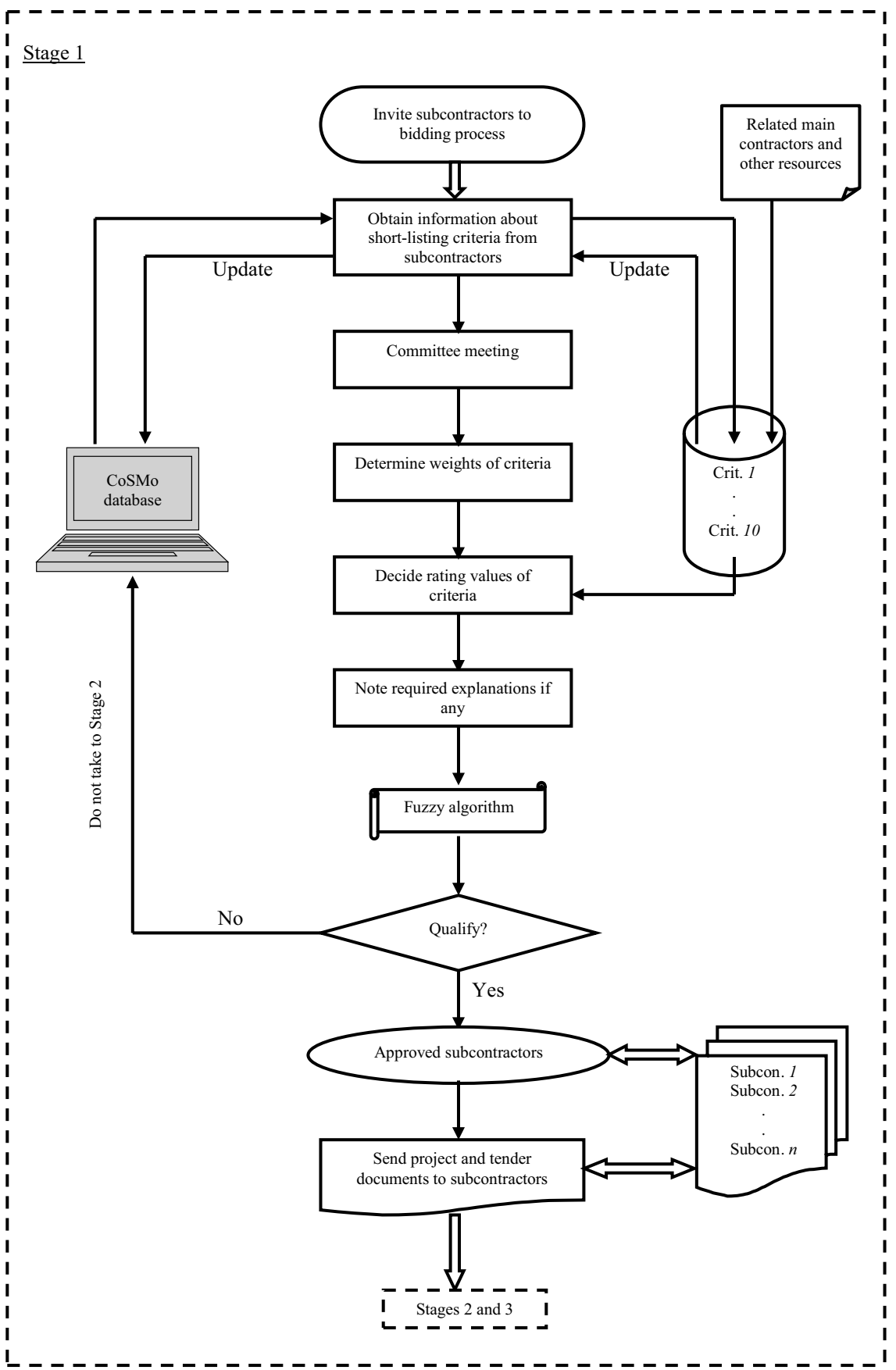

Fig. 5. Flow chart of the "short-listing" procedure 


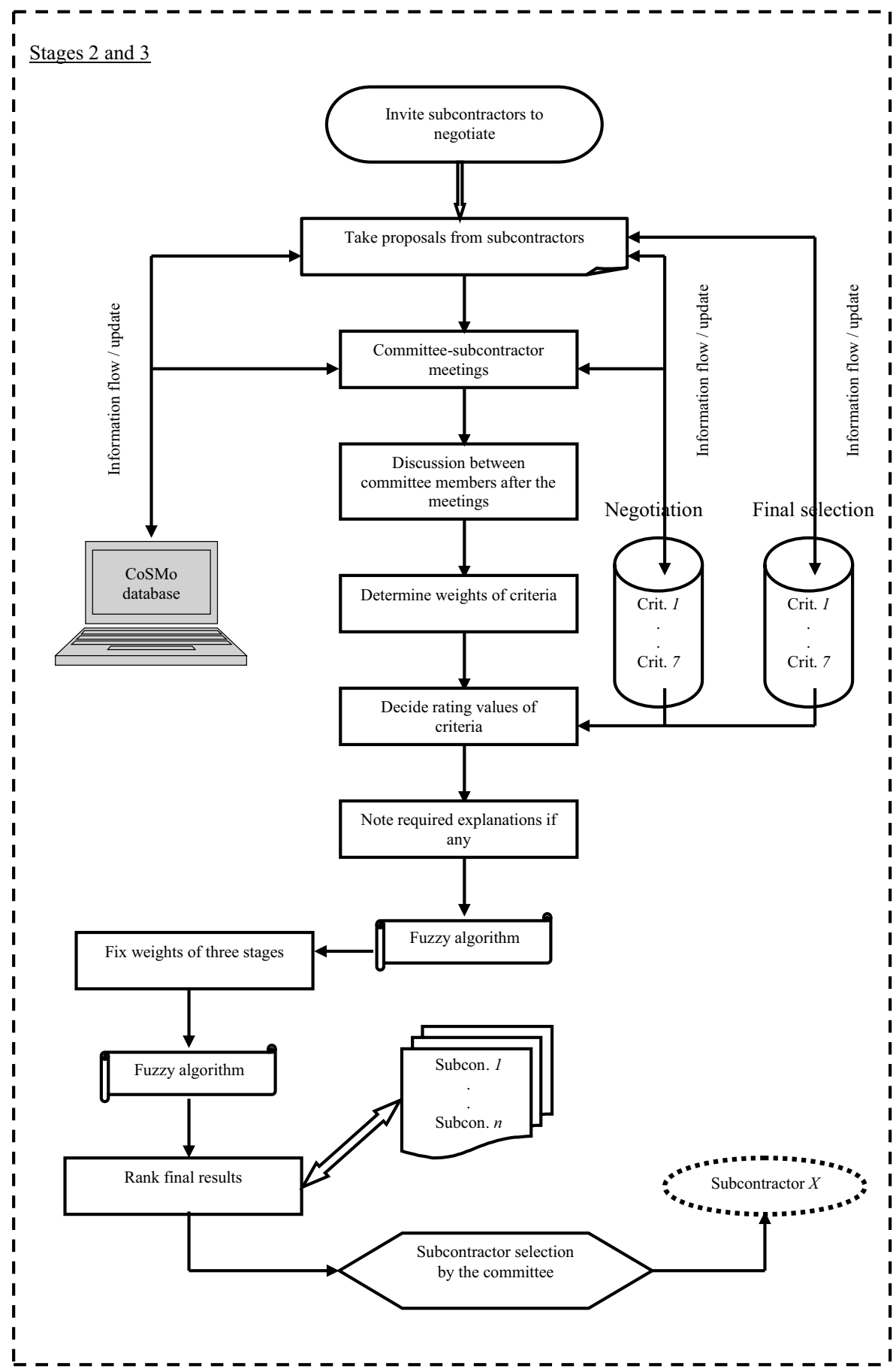

Fig. 6. Flow diagram of the "negotiation" and "final selection" procedures 
awareness, and level of communication. In fact, this stage is required to make evaluations on criteria of "negotiation" and "final selection" because (i) it is both time- and effort-consuming for the committee to take into account all of the candidate firms without applying any pre-qualification stage ("short-listing" in this model) and to negotiate with them in a detailed manner in the "short-listing" stage and (ii) "negotiation" and "final selection" stages focus on the detailed information about project-specific characteristics while "short-listing" is directly related with the core competencies of candidates. In terms of the "final selection" stage, there are seven more evaluation criteria such as price, technical personnel, labor, equipment, payment plan, amount of subcontracting, and amount of compensation for delay. After the meeting, committee members discuss for the ratings and weights of the criteria of "negotiation" and "final selection". In this process, necessary explanations should be noted to CoSMo especially regarding "final selection" criteria which are tangible in nature. Then, the fuzzy algorithm is automatically applied for "negotiation" and "final selection". For subcontractors who have qualified after "short-listing", the sum values of three stages are automatically appeared in the "outcome" form as rating scores of three stages. Finally, the committee determines weights of these three stages for the last automatic fuzzy calculation. This procedure ensures that high scores in one, perhaps less important area, do not hide a low score in another category. Finally, in the "briefing" form, the concluding results obtained in the "outcome" form are ranked and reported in a decreasing order. In this context, CoSMo gives an opportunity of making the last decision to the committee instead of calculating the top subcontractor only, and the results calculated for all candidates are reported in a ranking order. Accordingly, there is no obligation to select the top bidder. The committee can take a responsibility to award the second top bidder after investigating why it had a lower "outcome" value. However, if the difference between final results is larger than one scale, it is not recommended that the committee takes the initiative to choose the second top subcontractor.

\section{Case study}

To gain a better understanding of the current practice of subcontractor selection, a case of international construction works was considered. Thus, the applicability of CoSMo was also validated by conducting a real world construction project. The main contractor in this case study was from Turkey and has had experience in the international construction market for decades. The project for which the firm would choose a subcontractor was a multi-objective residence complex in Moscow, Russia. It contained a multi-storey building complex which was composed of luxurious office and dwelling areas, a car park, and a technical annexe. As usual, the main contractor would divide the project into several packages, and give each part to a subcontractor. In this case study, the subcontractor selection process for basic construction works was examined. A total of six subcontractors were interested in this package. From here, companies are denoted by SC1, SC2, SC3, SC4, SC5, and SC6 for confidentiality. SC1, SC2, and SC3 were the applicants for the package while SC4, SC5, and SC6 were the invited companies. SC1, SC4, and SC6 were Turkish firms, SC2 was a Russian firm, SC3 was a Ukrainian firm, and SC5 was an American firm. 
Linguistic ratings of 24 criteria and three stages were presented in Table 1 as a whole. In addition to these scores, their linguistic weights were also given in brackets. According to the data, the main contractor perceived "past experience", "selfless attitudes", and "enthusiasm for the project" as the most predominant criteria in his own selection strategy, while "amount of compensation for delay" was identified as the least important parameter. It was interesting that in the "final selection" stage there was no criterion perceived as "extremely high" in importance whereas in the "negotiation" stage there were two such criteria. This obviously showed how much important the intangible criteria could be. However, when all stages were taken into account together, "negotiation" was evaluated as the least important stage while "short-listing" was fixed as the most significant one. Nevertheless, importance levels placed on three stages were all above "high". The main contracting company established a subcontractor prequalification committee including a member of board of directors, project coordinator, proposal/tender manager, project manager, and site manager.

From previous experience with various subcontractors, the committee first reviewed the short-listing information about candidates and decided on the prequalified subcontractors. As an example, data and the result of "short-listing" for SC1 were illustrated in Figure 7.

For the "short-listing" stage, the selection problem including alternatives $(A)$ and criteria (C) was set up as follows:

$$
\begin{gathered}
A=\{S C 1, S C 2, S C 3, S C 4, S C 5, S C 6\}, \\
C=\{S 1, S 2, S 3, S 4, S 5, S 6, S 7, S 8, S 9, S 10\} .
\end{gathered}
$$

In this stage, the committee rated the subcontractors with respect to the ten criteria, as shown in Table 1. These ratings are fuzzy sets expressed in Zadeh's (1965) notation. For instance, the fuzzy set of S1 ("past experience") can be given as follows:

$$
S 1=\frac{M}{S C 1}+\frac{P}{S C 2}+\frac{P}{S C 3}+\frac{F G}{S C 4}+\frac{V G}{S C 5}+\frac{F G}{S C 6} .
$$

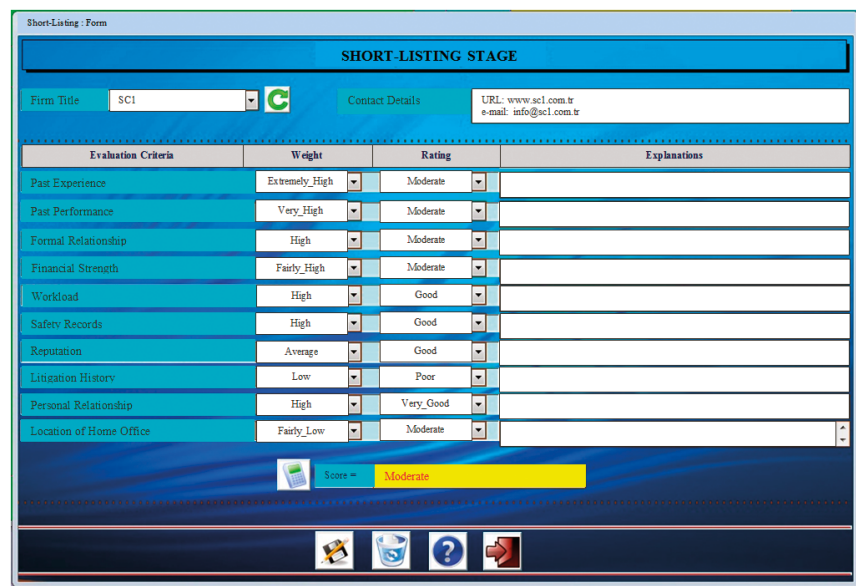

Fig. 7. Screen of the "short-listing" module 
Table 1. Linguistic ratings/weights of criteria and results of selection stages

\begin{tabular}{|c|c|c|c|c|c|c|c|c|c|c|c|}
\hline Stage & $\begin{array}{l}\text { Com- } \\
\text { pany }\end{array}$ & $\begin{array}{c}\mathrm{S} 1 \\
(\mathrm{EH})\end{array}$ & $\begin{array}{c}\mathrm{S} 2 \\
(\mathrm{VH})\end{array}$ & $\begin{array}{l}\text { S3 } \\
(\mathrm{H})\end{array}$ & $\begin{array}{c}\mathrm{S} 4 \\
(\mathrm{FH})\end{array}$ & $\begin{array}{c}\text { S5 } \\
(\mathrm{H})\end{array}$ & $\begin{array}{l}\text { S6 } \\
(\mathrm{H})\end{array}$ & $\begin{array}{l}\text { S7 } \\
\text { (A) }\end{array}$ & $\begin{array}{l}\text { S8 } \\
\text { (L) }\end{array}$ & $\begin{array}{c}\text { S9 } \\
(\mathrm{H})\end{array}$ & $\begin{array}{l}\text { S10 } \\
\text { (FL) }\end{array}$ \\
\hline \multirow{6}{*}{$\begin{array}{l}\text { Short- } \\
\text { listing }\end{array}$} & SC1 & $\mathrm{M}$ & $\mathrm{M}$ & $\mathrm{M}$ & $\mathrm{M}$ & G & G & G & $\mathrm{P}$ & VG & $\mathrm{M}$ \\
\hline & SC2 & $\mathrm{P}$ & G & $\mathrm{M}$ & M & FG & $\mathrm{P}$ & $\mathrm{P}$ & $\mathrm{E}$ & $\mathrm{M}$ & $\mathrm{E}$ \\
\hline & SC3 & $\mathrm{P}$ & FG & $\mathrm{M}$ & $M$ & VG & VP & $\mathrm{VP}$ & $E$ & $\mathrm{M}$ & FG \\
\hline & SC4 & FG & $\mathrm{G}$ & $\mathrm{G}$ & $\mathrm{G}$ & G & FG & G & $E$ & $E$ & $\mathrm{M}$ \\
\hline & SC5 & VG & FG & FG & $\mathrm{E}$ & FG & $\mathrm{E}$ & $\mathrm{E}$ & $\mathrm{E}$ & VG & VG \\
\hline & SC6 & FG & $\mathrm{FG}$ & $\mathrm{VG}$ & VG & FG & $\mathrm{VG}$ & VG & $E$ & VG & $M$ \\
\hline \multirow{5}{*}{$\begin{array}{l}\text { Nego- } \\
\text { tiation }\end{array}$} & \multicolumn{2}{|c|}{ Company } & $\begin{array}{l}\text { N1 } \\
(\mathrm{H})\end{array}$ & $\begin{array}{c}\mathrm{N} 2 \\
(\mathrm{FH})\end{array}$ & \multicolumn{2}{|l|}{$\begin{array}{c}\mathrm{N} 3 \\
(\mathrm{EH})\end{array}$} & $\begin{array}{c}\mathrm{N} 4 \\
\text { (VH) }\end{array}$ & $\begin{array}{c}\text { N5 } \\
\text { (EH) }\end{array}$ & \multicolumn{2}{|c|}{$\begin{array}{c}\mathrm{N6} \\
\text { (VH) }\end{array}$} & $\begin{array}{l}\text { N7 } \\
\text { (A) }\end{array}$ \\
\hline & \multicolumn{2}{|l|}{ SC1 } & VG & FG & \multicolumn{2}{|l|}{ VG } & $\mathrm{M}$ & $\mathrm{M}$ & \multicolumn{2}{|c|}{$\mathrm{M}$} & G \\
\hline & \multicolumn{2}{|l|}{ SC4 } & E & FG & \multicolumn{2}{|l|}{ VG } & FG & G & \multicolumn{2}{|c|}{ FG } & VG \\
\hline & \multicolumn{2}{|l|}{ SC5 } & $E$ & FG & \multicolumn{2}{|l|}{ FG } & FG & VG & \multicolumn{2}{|c|}{ VG } & FG \\
\hline & \multicolumn{2}{|l|}{ SC6 } & $E$ & VG & \multicolumn{2}{|l|}{ VG } & VG & $E$ & \multicolumn{2}{|c|}{ VG } & VG \\
\hline \multirow{5}{*}{$\begin{array}{l}\text { Final } \\
\text { selec- } \\
\text { tion }\end{array}$} & \multicolumn{2}{|c|}{ Company } & $\begin{array}{c}\mathrm{F} 1 \\
(\mathrm{FH})\end{array}$ & $\begin{array}{c}\mathrm{F} 2 \\
(\mathrm{VH})\end{array}$ & \multicolumn{2}{|l|}{$\begin{array}{c}\mathrm{F} 3 \\
(\mathrm{FH})\end{array}$} & $\begin{array}{l}\mathrm{F} 4 \\
(\mathrm{H})\end{array}$ & $\begin{array}{l}\text { F5 } \\
\text { (A) }\end{array}$ & \multicolumn{2}{|c|}{$\begin{array}{c}\text { F6 } \\
\text { (VL) }\end{array}$} & $\begin{array}{c}\text { F7 } \\
\text { (EL) }\end{array}$ \\
\hline & SC1 & & FG & $\mathrm{M}$ & \multicolumn{2}{|l|}{$\mathrm{G}$} & $M$ & $\mathrm{M}$ & \multicolumn{2}{|c|}{ FG } & $\mathrm{M}$ \\
\hline & SC4 & & G & FG & $\mathrm{G}$ & & G & $E$ & & & $\mathrm{M}$ \\
\hline & SC5 & & VG & VG & FG & & VG & FG & & & VG \\
\hline & SC6 & & FG & FG & VG & & FG & FG & & & G \\
\hline & Con & pany & & $\begin{array}{c}\text { SS } \\
(\mathrm{EH})\end{array}$ & & $\begin{array}{c}\text { SN } \\
(\mathrm{FH})\end{array}$ & & $\begin{array}{c}\text { SF } \\
(\mathrm{VH})\end{array}$ & & $\begin{array}{r}\mathrm{S} \\
\mathrm{Con} \\
\mathrm{res}\end{array}$ & $\begin{array}{l}\text { uding } \\
\text { lt) }\end{array}$ \\
\hline & & & & $M$ & & $\mathrm{M}$ & & $\mathrm{M}$ & & & \\
\hline Out- & & & & $\mathrm{P}$ & Out of & f evalu & uation & Out of evalu & ation & Unqu & lified \\
\hline & & & & $\mathrm{P}$ & Out of & f evalu & uation & Out of evalu & ation & Unqu & lified \\
\hline & & & & $G$ & & G & & G & & & \\
\hline & & & & FG & & FG & & FG & & & \\
\hline & & & & FG & & VG & & FG & & & \\
\hline
\end{tabular}

Note: S1: Past experience; S2: Past performance; S3: Formal relationship; S4: Financial strength; S5: Workload; S6: Safety records; S7: Reputation; S8: Litigation history; S9: Personal relationship; S10: Location of home office.

N1: Knowledge of project; N2: Reliability; N3: Selfless attitudes; N4: Ability to solve problems; N5: Enthusiasm for the project; N6: Quality awareness; N7: Level of communication.

F1: Price; F2: Technical personnel; F3: Labor; F4: Equipment; F5: Payment plan; F6: Amount of subcontracting; F7: Amount of compensation for delay.

SS: The sum of short-listing; SN: The sum of negotiation; SF: The sum of final selection; SO: The sum of outcome.

N: None; VP: Very poor; FP: Fairly poor; P: Poor; M: Moderate; G: Good; FG: Fairly good; VG: Very good; E: Excellent.

EL: Extremely low; VL: Very low; FL: Fairly low; L: Low; A: Average; H: High; FH: Fairly high; VH: Very high; EH: Extremely high. 
This kind of membership functions for each of the alternatives was formed in further calculations. The committee listed its preferences (weights), the set of " $b$ ", for each of the ten criteria. These were also shown in Table 1 in brackets under criteria symbols. From these preference values, the following calculations resulted:

$$
\begin{gathered}
b=\{E H, V H, H, F H, H, H, A, L, H, F L\}= \\
\quad\{0.9,0.8,0.6,0.7,0.6,0.6,0.5,0.4,0.6,0.3\} ; \\
\bar{b}=\{0.1,0.2,0.4,0.3,0.4,0.4,0.5,0.6,0.4,0.7\} .
\end{gathered}
$$

Solving the problem for SC1 as an example, the following result was obtained:

$$
\begin{aligned}
& D(S C 1)=\left(\overline{b_{1}} \cup S 1\right) \cap\left(\overline{b_{2}} \cup S 2\right) \cap\left(\overline{b_{3}} \cup S 3\right) \cap\left(\overline{b_{4}} \cup S 4\right) \cap\left(\overline{b_{5}} \cup S 5\right) \cap \\
& \left(\overline{b_{6}} \cup S 6\right) \cap\left(\overline{b_{7}} \cup S 7\right) \cap\left(\overline{b_{8}} \cup S 8\right) \cap\left(\overline{b_{9}} \cup S 9\right) \cap\left(\overline{b_{10}} \cup S 10\right)= \\
& \left(0.1 \cup^{0.5}\right) \cap\left(0.2 \cup^{0.5}\right) \cap\left(0.4 \cup^{0.5}\right) \cap\left(0.3 \cup^{0.5}\right) \cap\left(0.4 \cup^{0.6}\right) \cap \\
& \left(0.4 \cup^{0.6}\right) \cap\left(0.5 \cup^{0.6}\right) \cap\left(0.6 \cup^{0.4}\right) \cap\left(0.4 \cup^{0.8}\right) \cap\left(0.7 \cup^{0.5}\right)= \\
& 0.5 \bigcap^{0.5} \bigcap^{0.5} \bigcap^{0.5} \bigcap^{0.6} \bigcap^{0.6} \bigcap^{0.6} \bigcap^{0.6} \bigcap^{0.8} \bigcap^{0.7}=0.5(M) .
\end{aligned}
$$

At the end of this "short-listing" stage, the resultant values of SC2 and SC3 were calculated as "poor", i.e., lower than the threshold "moderate". Therefore, these subcontractors were neither evaluated nor screened in the remaining two stages and were reported as "unqualified" in the "briefing" form. In this context, SC1, SC4, SC5, and SC6 were the bidders that could pass to "negotiation" and "final selection". To be graphical examples, data and results of "negotiation" and "final selection" for SC1 were respectively illustrated in Figures 8 and 9.

For the "negotiation" stage, the problem including alternatives $(A)$ and criteria $(C)$ was formed as follows:

$$
\begin{gathered}
A=\{S C 1, S C 4, S C 5, S C 6\} ; \\
C=\{N 1, N 2, N 3, N 4, N 5, N 6, N 7\} .
\end{gathered}
$$

Here, the committee rated these four subcontractors with respect to the seven criteria (Table 1). The fuzzy set of N1 ("knowledge of project") can be given as an example:

$$
N 1=\frac{V G}{S C 1}+\frac{E}{S C 4}+\frac{E}{S C 5}+\frac{E}{S C 6} .
$$

The committee listed its preferences (the set of " $b$ ") for each of the seven criteria (Table 1). From these preference values, the following calculations resulted:

$$
\begin{gathered}
b=\{H, F H, E H, V H, E H, V H, A\}=0.6,0.7,0.9,0.8,0.9,0.8,0.5 ; \\
\bar{b}=\{0.4,0.3,0.1,0.2,0.1,0.2,0.5\} .
\end{gathered}
$$


Solving the problem for SC1 as an instance, the following result was calculated:

$$
\begin{aligned}
& D(S C 1)=\left(\overline{b_{1}} \cup N 1\right) \cap\left(\overline{b_{2}} \cup N 2\right) \cap\left(\overline{b_{3}} \cup N 3\right) \cap\left(\overline{b_{4}} \cup N 4\right) \cap \\
& \left(\overline{b_{5}} \cup N 5\right) \cap\left(\overline{b_{6}} \cup N 6\right) \cap\left(\overline{b_{7}} \cup N 7\right)= \\
& \left(0.4 \cup^{0.8}\right) \cap\left(0.3 \cup^{0.7}\right) \cap\left(0.1 \cup^{0.8}\right) \cap\left(0.2 \cup^{0.5}\right) \cap \\
& \left(0.1 \cup^{0.5}\right) \cap\left(0.2 \cup^{0.5}\right) \cap\left(0.5 \cup^{0.6}\right)= \\
& 0.8 \cap^{0.7} \cap^{0.8} \cap^{0.5} \cap^{0.5} \cap^{0.5} \cap^{0.6=0.5(M) .}
\end{aligned}
$$

Similarly, for the "final selection" stage, the problem including alternatives $(A)$ and criteria (C) was formed as follows:

$$
\begin{gathered}
A=\{S C 1, S C 4, S C 5, S C 6\} ; \\
C=\{F 1, F 2, F 3, F 4, F 5, F 6, F 7\} .
\end{gathered}
$$

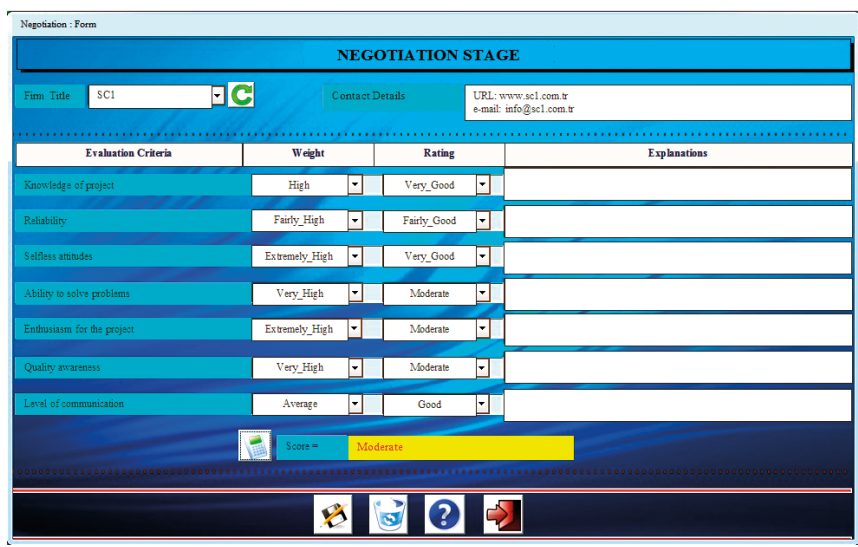

Fig. 8. Screen of the "negotiation" module

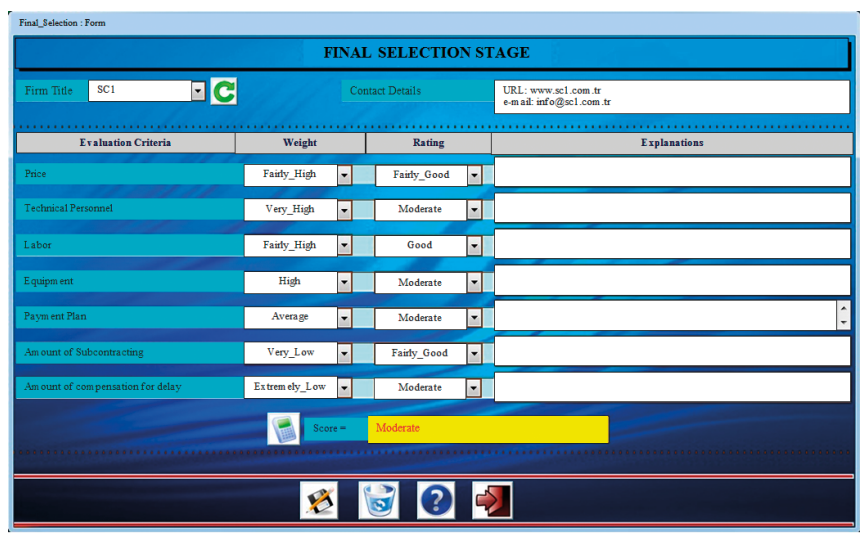

Fig. 9. Screen of the "final selection" module 
The committee rated these four subcontractors with respect to the seven criteria (Table 1). The fuzzy set of F1 ("price") can be given as follows:

$$
F 1=\frac{F G}{S C 1}+\frac{G}{S C 4}+\frac{V G}{S C 5}+\frac{F G}{S C 6} .
$$

The committee listed its preferences, the set of " $b$ ", for each of the seven criteria (Table 1). From these preference values, the following calculations resulted:

$$
\begin{gathered}
b=\{F H, V H, F H, H, A, V L, E L\}=\{0.7,0.8,0.7,0.6,0.5,0.2,0.1\} ; \\
\bar{b}=\{0.3,0.2,0.3,0.4,0.5,0.8,0.9\} .
\end{gathered}
$$

Solving the problem for SC1 as an example, the following result was obtained:

$$
\begin{aligned}
& D(S C 1)=\left(\overline{b_{1}} \cup F 1\right) \cap\left(\overline{b_{2}} \cup F 2\right) \cap\left(\overline{b_{3}} \cup F 3\right) \cap\left(\overline{b_{4}} \cup F 4\right) \cap \\
& \left(\overline{b_{5}} \cup F 5\right) \cap\left(\overline{b_{6}} \cup F 6\right) \cap\left(\overline{b_{7}} \cup F 7\right)= \\
& \left(0.3 \cup^{0.7}\right) \cap\left(0.2 \cup^{0.5}\right) \cap\left(0.3 \cup^{0.6}\right) \cap\left(0.4 \cup^{0.5}\right) \cap \\
& (0.5 \cup 0.5) \cap(0.8 \cup 0.7) \cap(0.9 \cup 0.5)= \\
& 0.7 \bigcap^{0.5} \bigcap^{0.6} \bigcap^{0.5} \bigcap^{0.5} \bigcap^{0.8} \bigcap^{0.9}=0.5(M) .
\end{aligned}
$$

For each subcontractor, the results of the "outcome" stage were calculated. As an instance, data and the result of "outcome" for SC1 were illustrated in Figure 10.

For the "outcome" stage, the selection problem including alternatives $(A)$ and criteria $(C)$ was set up as follows:

$$
\begin{gathered}
A=\{S C 1, S C 4, S C 5, S C 6\} ; \\
C=\{S S, S N, S F\} .
\end{gathered}
$$

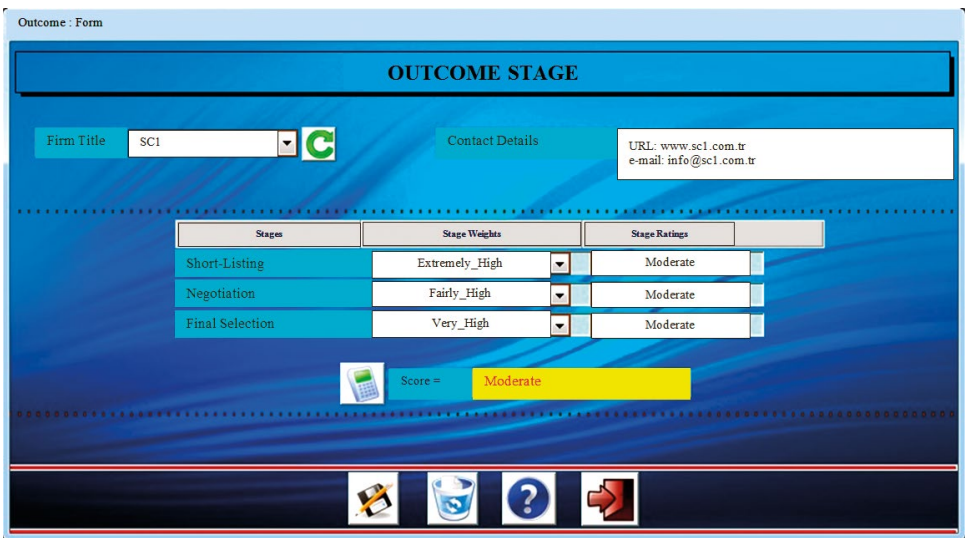

Fig. 10. Screen of the "outcome" module 
As criteria in this step are selection stages, their rating values were automatically taken from stage results for each subcontractor (Table 1). For example, the fuzzy set of SS ("the sum of short-listing") can be given as follows:

$$
S S=\frac{M}{S C 1}+\frac{G}{S C 4}+\frac{F G}{S C 5}+\frac{F G}{S C 6} .
$$

The committee listed its preferences, the set of " $b$ ", for each of the three stages (Table 1). From these preference values, the following calculations resulted:

$$
\begin{gathered}
b=\{E H, F H, V H\}=\{0.9,0.7,0.8\} ; \\
\bar{b}=\{0.1,0.3,0.2\} .
\end{gathered}
$$

Solving the problem for SC1 as an instance, the following result was calculated:

$$
\begin{aligned}
D(S C 1)= & \left(\overline{b_{1}} \cup S S\right) \cap\left(\overline{b_{2}} \cup S N\right) \cap\left(\overline{b_{3}} \cup S F\right)= \\
& (0.1 \cup 0.5) \cap(0.3 \cup 0.5) \cap(0.2 \cup 0.5)= \\
& 0.5 \cap 0.5 \cap 0.5=0.5(M) .
\end{aligned}
$$

In the "briefing" module, the concluding rankings shown in Figure 11 were obtained. In conclusion, the committee determined SC5 and SC6 as the top two bidders.

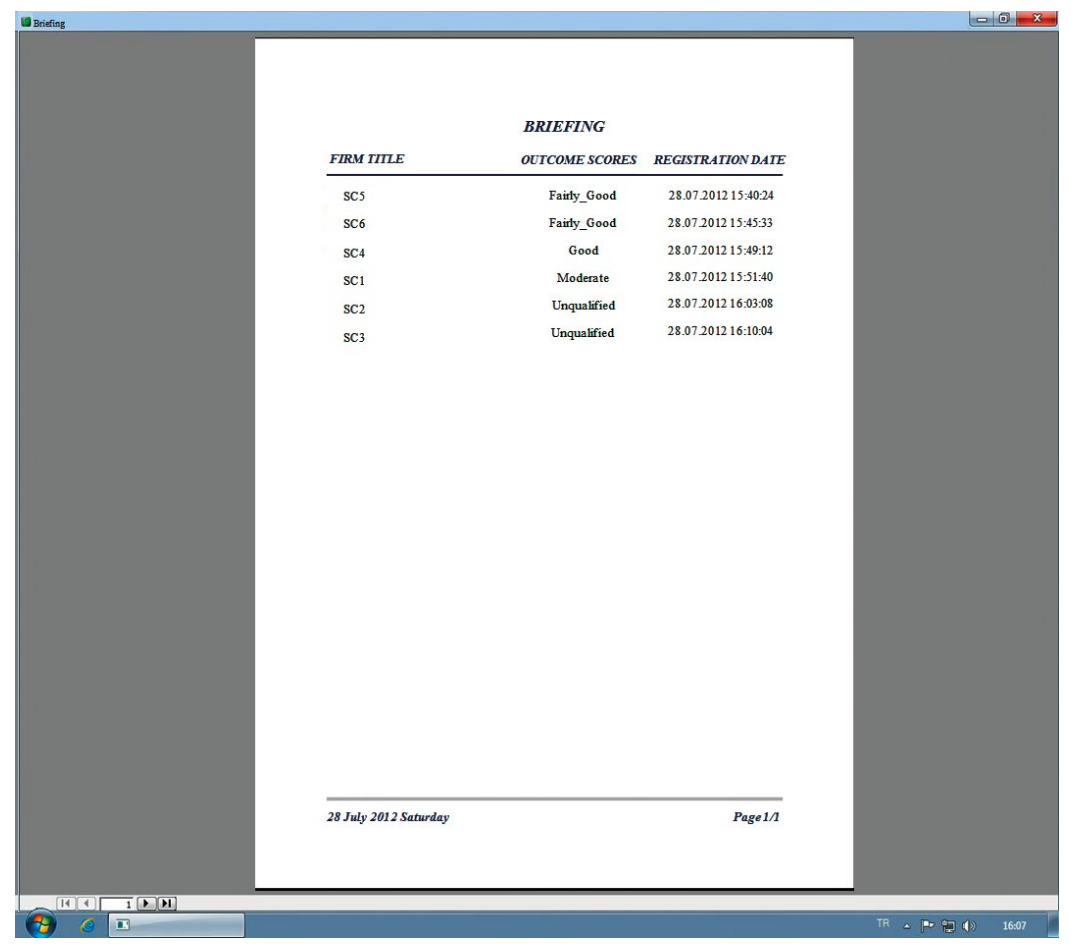

Fig. 11. Screen of the "briefing" module 


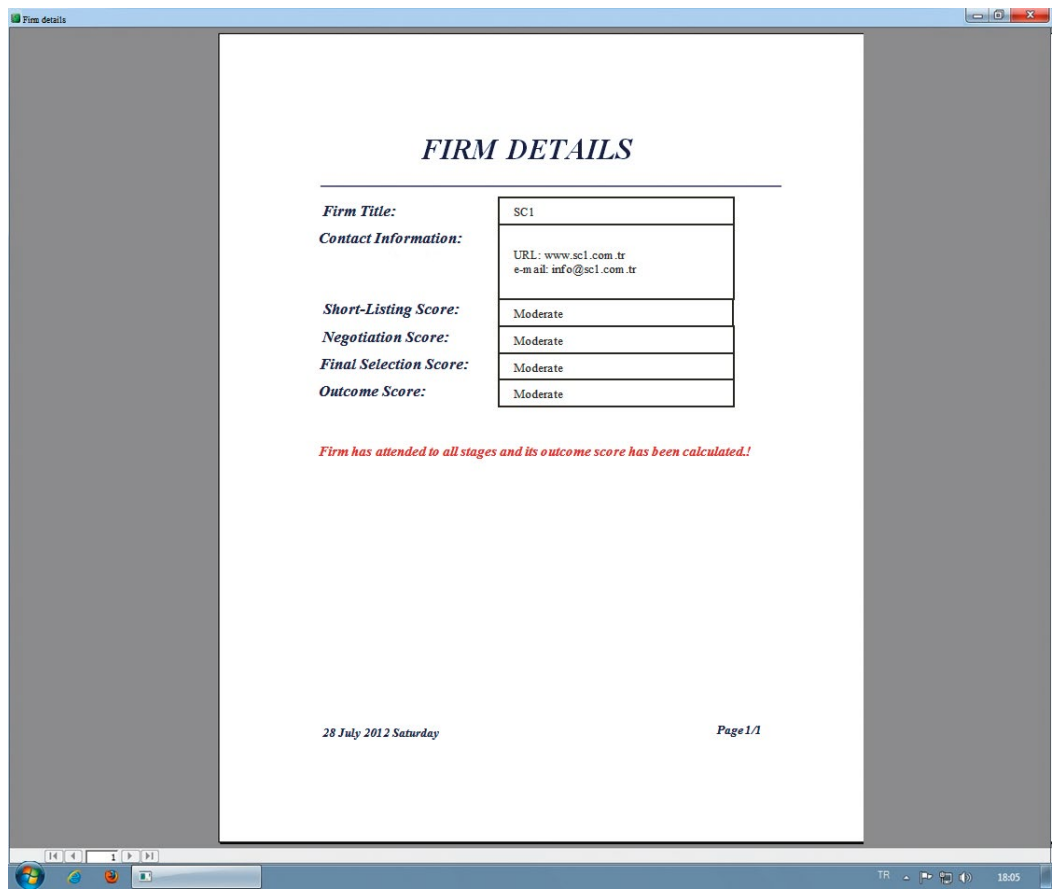

Fig. 12. Screen of the "firm details" page in the "information on firms" module

When desired, as shown in Figure 12, each subcontractor's partial scores can be viewed as a whole in one page (the "firm details" page) from the "information on firms" module in the main menu presented in Figure 3.

As there were two equal winners of the subcontracting package, an important issue in practice was taken into account by the committee. Since subcontractors in the same or successive activities work in an interactive manner with each other, cooperation and communication between them should be problem-free. This issue may likely turn to a vital problem in international construction projects where cultural differences between crews can have utmost importance. The traditional way to subcontract a project does not allow for thorough evaluation of the interdependence of various participating entities in each project, and generally cuts each specific project into several completely independent subcontracts. However, a general contractor should consider the entire subcontracting supply chain of projects because what is individually optimal combination may not necessarily result in the best global outcome. Therefore, in order to reach better harmony between real physical constructers of projects and thereby to obtain a better-quality final product, subcontractors who have worked together in previous projects can be employed. While using too many subcontractors and second-tier subcontractors in a large-scale construction project, supervising and controlling become more difficult for principal contractors and extra conflicts can rise between crews. Olsson (1998) explains that several main contractors in Sweden use a special subcontract coordinator before and during construction in an effort to reduce problems. 
As a result, whether healthy working environment between the selected two firms and the other potential subcontractors that might undertake the remaining work packages of the project could be established was taken into account by the committee. After investigating past experiences of subcontractors who have applied to be awarded for several packages of final construction works, the committee determined that SC6 has worked with the majority of these applicants in harmony in past international projects. Consequently, the committee decided to employ SC6 instead of SC5, and presented the decision letter and the attached printout reports of each stage of CoSMo to the approval of Board of Directors. At last, SC6 was awarded after the approval.

\section{Conclusions}

In this study, a computer-aided subcontractor selection model called CoSMo that can help a project contractor in conducting a prequalification assessment among various combinations of on-list subcontractors was introduced. The mission of this computational model is to emphasize the importance and necessity of the subcontractor selection problem in international construction projects. The model presented in this study can be described as a dynamic, reliable, and practical automation system that was created to choose the most suitable subcontractor for a specific project package rather than the "best" subcontracting firm in absolute terms. Selecting the most appropriate tender with high confidence, in turn, help in reducing the effort and time consumed in the evaluation process. General contractors can thus concentrate on attracting professional subcontractors who will bring and produce quality work, which will ultimately have a significant impact on improving the main contractors' business reputation. It should also be noted that the results obtained by CoSMo are completely human-dependent and that each decision strategy is subject to biases of the decision maker(s). In this respect, the results presented provide insight into how decision makers view their decision factors in the subcontractor prequalification. Subcontractor selection inputs themselves are critical procurement aspects that should be tailored to match project objectives despite the fact that decision-makers may give different weights of importance to the same criterion and give different values of a criterion for each subcontractor over time. Toward this aim, in recognition of the changes of preference in relation to a particular situation, CoSMo allows decision-makers to change weights and ratings of criteria and stages as required. This option provides flexibility for CoSMo. In addition, since different decision models may provide different solutions, CoSMo can be used as a benchmark dictionary by potential researchers in the future. However, in this study, it cannot be claimed that perfect or the best decision-making model was found out, because all of decision methodologies are based on particular theoretical acceptances together with limitations and each aid has some disadvantages in arriving at a solution. Nevertheless, users should be aware of limitations of any technique. For the present study, it is recommended that CoSMo users may exercise different scenarios based on their changeable or indecisive judgments on ratings and weights. The fact that the "briefing" module in CoSMo shows the final ranking of candidates instead of giving only one result addresses this notion. The novel architecture for the subcontractor selection in a fuzzy environment presented can be easily extended to other managerial and industrial decision-making problems. 
As an on-going research, a detailed computer-supported subcontractor resource module where CoSMo will be integrated into a project management software as a component is still being developed. Therefore, this study solely proposes a preliminary model to establish a standardized environment to accelerate the subcontracting procurement process of a construction project. In this module to be developed, when the decision maker picks the awarded subcontractor on the CoSMo screen, all the resource information (labor and equipment) of this firm will be automatically transferred to the module. In the main project program, time and cost schedules of project activities that will be executed by the subcontractor will then be formed instantly. Hence, both the subcontractor selection and the related planning efforts will be carried out in one time.

\section{Acknowledgements}

The authors gratefully acknowledge the managers of the surveyed company for their generous collaboration and contributions. The authors also thank the anonymous referees for their constructive comments which have helped in improving the paper. Finally, the authors would like to thank the financial supports provided by the Committees on Research Grants of Bulent Ecevit University and Akdeniz University.

\section{References}

Albino, V.; Garavelli, A. C. 1998. A neural network application to subcontractor rating in construction firms, International Journal of Project Management 16(1): 9-14. http://dx.doi.org/10.1016/S0263-7863(97)00007-0

Arditi, D.; Chotibhongs, R. 2005. Issues in subcontracting practice, Journal of Construction Engineering and Management 131(8): 866-876. http://dx.doi.org/10.1061/(ASCE)0733-9364(2005)131:8(866)

Arslan, G. 2012. Web-based contractor evaluation system for mass-housing projects in Turkey, Journal of Civil Engineering and Management 18(3): 323-334. http://dx.doi.org/10.3846/13923730.2012.698892

Arslan, G.; Kivrak, S.; Birgonul, M. T.; Dikmen, I. 2008. Improving sub-contractor selection process in construction projects: web-based sub-contractor evaluation system (WEBSES), Automation in Construction 17(4): 480-488. http://dx.doi.org/10.1016/j.autcon.2007.08.004

Brauers, W. K. M.; Zavadskas, E. K.; Turskis, Z.; Vilutiene, T. 2008. Multi-objective contractor's ranking by applying the MOORA method, Journal of Business Economics and Management 9(4): 245-255. http://dx.doi.org/10.3846/1611-1699.2008.9.245-255

Chen, S. J.; Hwang, C. L. 1992. Fuzzy multiple attribute decision-making method and applications. New York: Springer-Verlag. http://dx.doi.org/10.1007/978-3-642-46768-4

Cheng, M. Y.; Kang, S. T. 2012. Integrated fuzzy preference relations with decision utilities for construction contractor selection, Journal of the Chinese Institute of Engineers 35(8): 1051-1063. http://dx.doi.org/10.1080/02533839.2012.708510

Chiang, Y. H. 2009. Subcontracting and its ramifications: a survey of the building industry in Hong Kong, International Journal of Project Management 27(1): 80-88. http://dx.doi.org/10.1016/j.ijproman.2008.01.005

Choudhry, R. M.; Hinze, J. W.; Arshad, M.; Gabriel, H. F. 2012. Subcontracting practices in the construction industry of Pakistan, Journal of Construction Engineering and Management 138(12): 1353-1359. http://dx.doi.org/10.1061/(ASCE)CO.1943-7862.0000562 
De Silva, D. G.; Kosmopoulou, G.; Lamarche, C. 2012. Survival of contractors with previous subcontracting experience, Economic Letters 117: 7-9. http://dx.doi.org/10.1016/j.econlet.2012.04.071

Elton, D. J.; Juang, C. H.; Russell, J. S. 1994. Contractor prequalification using fuzzy sets, Civil Engineering Systems 11: 1-17. http://dx.doi.org/10.1080/02630259408970134

Grasso, B.; Rasdorf, W.; Bridgers, M. 2008. Nature and extent of domestic construction program outsourcing, Journal of Construction Engineering and Management 134(12): 1002-1010. http://dx.doi.org/10.1061/(ASCE)0733-9364(2008)134:12(1002)

Hinze, J.; Tracey, A. 1994. The contractor-subcontractor relationship: the subcontractor's point of view, Journal of Construction Engineering and Management 120(2): 274-287. http://dx.doi.org/10.1061/(ASCE)0733-9364(1994)120:2(274)

Holt, G. D. 1998. Which contractor selection methodology?, International Journal of Project Management 16(3): 153-164. http://dx.doi.org/10.1016/S0263-7863(97)00035-5

Ip, W. H.; Yung, K. L.; Wang, D. 2004. A branch and bound algorithm for sub-contractor selection in agile manufacturing environment, International Journal of Production Economics 87: 195-205. http://dx.doi.org/10.1016/S0925-5273(03)00125-7

Juang, C. H.; Burati, J. L.; Kalindindi, S. N. 1987. A fuzzy system for bid proposal evaluation using microcomputers, Civil Engineering Systems 4(3): 124-130. http://dx.doi.org/10.1080/02630258708970474

Kazaz, A.; Ulubeyli, S.; Tuncbilekli, N. A. 2012. Causes of delays in construction projects in Turkey, Journal of Civil Engineering and Management 18(3): 426-435. http://dx.doi.org/10.3846/13923730.2012.698913

Kumaraswamy, M. M.; Matthews, J. D. 2000. Improved subcontractor selection employing partnering principles, Journal of Management in Engineering 16(3): 47-57. http://dx.doi.org/10.1061/(ASCE)0742-597X(2000)16:3(47)

Lashgari, A.; Yazdani-Chamzini, A.; Fouladgar, M. M.; Zavadskas, E. K.; Shafiee, S.; Abbate, N. 2012. Equipment selection using fuzzy multi criteria decision making model: key study of Gole Gohar Iron Mine, Inzinerine Ekonomika - Engineering Economics 23(2): 125-136.

Lingard, H. C.; Cooke, T.; Blismas, N. 2010. Safety climate in conditions of construction subcontracting: a multi-level analysis, Construction Management and Economics 28: 813-825.

http://dx.doi.org/10.1080/01446190903480035

Mbachu, J. 2008. Conceptual framework for the assessment of subcontractors' eligibility and performance in the construction industry, Construction Management and Economics 26: 471-484.

http://dx.doi.org/10.1080/01446190801918730

Miller, G. A. 1965. The magic number seven, plus or minus seven, Psychological Review 63: 81-97. http://dx.doi.org/10.1037/h0043158

Mitkus, S.; Trinkuniene, E. 2008. Reasoned decisions in construction contracts evaluation, Technological and Economic Development of Economy 14(3): 402-416. http://dx.doi.org/10.3846/1392-8619.2008.14.402-416

Ng, S. T.; Luu, C. D. T. 2008. Modeling subcontractor registration decisions through case-based reasoning approach, Automation in Construction 17(7): 873-881. http://dx.doi.org/10.1016/j.autcon.2008.02.015

Ng, S. T.; Tang, Z. 2010. Labour-intensive construction sub-contractors: their critical success factors, International Journal of Project Management 28: 732-740. http://dx.doi.org/10.1016/j.ijproman.2009.11.005

Nguyen, V. U. 1985. Tender evaluation by fuzzy sets, Journal of Construction Engineering and Management 111(3): 231-243. http://dx.doi.org/10.1061/(ASCE)0733-9364(1985)111:3(231)

Okoroh, M. I.; Torrance, V. B. 1999. A model for subcontractor selection in refurbishment projects, Construction Management and Economics 17(3): 315-327. http://dx.doi.org/10.1080/014461999371529

Olsson, R. 1998. Subcontract coordination in construction, International Journal of Production Economics 56-57: 503-509. http://dx.doi.org/10.1016/S0925-5273(97)00024-8 
Paek, J. H.; Lee, Y. W.; Napier, T. R. 1992. Selection of design/build proposal using fuzzy-logic system, Journal of Construction Engineering and Management 118(2): 303-317. http://dx.doi.org/10.1061/(ASCE)0733-9364(1992)118:2(303)

Plebankiewicz, E. 2009. Contractor prequalification model using fuzzy sets, Journal of Civil Engineering and Management 15(4): 377-385. http://dx.doi.org/10.3846/1392-3730.2009.15.377-385

Plebankiewicz, E. 2010. Construction contractor prequalification from Polish clients' perspective, Journal of Civil Engineering and Management 16(1): 57-64. http://dx.doi.org/10.3846/jcem.2010.05

Podvezko, V.; Mitkus, S.; Trinkuniene, E. 2010. Complex evaluation of contracts for construction, Journal of Civil Engineering and Management 16(2): 287-297. http://dx.doi.org/10.3846/jcem.2010.33

Poyhonen, M. A.; Hamalainen, R. P.; Salo, A. A. 1997. An experiment on the numerical modelling of verbal ratio statements, Journal of Multi-Criteria Decision Analysis 6(1): 1-10.

http://dx.doi.org/10.1002/(SICI)1099-1360(199701)6:1<1::AID-MCDA111>3.0.CO;2-W

Ragin, C. C. 2000. Fuzzy-set social science. Chicago: University of Chicago Press.

Ross, T. J. 1997. Fuzzy logic with engineering applications. Singapore: McGraw Hill.

San Cristobal, J. R. 2012. Contractor selection using multicriteria decision-making methods, Journal of Construction Engineering and Management 138(6): 751-758. http://dx.doi.org/10.1061/(ASCE)CO.1943-7862.0000488

Shash, A. A. 1998. Bidding practices of subcontractors in Colorado, Journal of Construction Engineering and Management 124(3): 219-225. http://dx.doi.org/10.1061/(ASCE)0733-9364(1998)124:3(219)

Singh, D.; Tiong, R. L. K. 2005. A fuzzy decision framework for contractor selection, Journal of Construction Engineering and Management 131(1): 62-70.

http://dx.doi.org/10.1061/(ASCE)0733-9364(2005)131:1(62)

Smithson, M.; Verkuilen, J. 2006. Fuzzy set theory: applications in the social sciences. California: Sage.

Tam, V. W. Y.; Shen, L. Y.; Kong, J. S. Y. 2011. Impacts of multi-layer chain subcontracting on project management performance, International Journal of Project Management 29: 108-116. http://dx.doi.org/10.1016/j.ijproman.2010.01.005

Tserng, H. P.; Lin, P. H. 2002. An accelerated subcontracting and procuring model for construction projects, Automation in Construction 11: 105-125. http://dx.doi.org/10.1016/S0926-5805(01)00056-5

Turskis, Z. 2008. Multi-attribute contractors ranking method by applying ordering of feasible alternatives of solutions in terms of preferability technique, Technological and Economic Development of Economy 14(2): 224-239. http://dx.doi.org/10.3846/1392-8619.2008.14.224-239

Ulubeyli, S. 2008. Fuzzy multiple criteria decision making model for subcontractor selection in international construction projects: $\mathrm{PhD}$ Thesis. Istanbul University, Turkey.

Ulubeyli, S.; Manisali, E.; Kazaz, A. 2010. Subcontractor selection practices in international construction projects, Journal of Civil Engineering and Management 16(1): 47-56. http://dx.doi.org/10.3846/jcem.2010.04

Vahdani, B.; Mousavi, S. M.; Hashemi, H.; Mousakhani, M.; Moghaddam, R. T. 2013. A new compromise solution method for fuzzy group decision-making problems with an application to the contractor selection, Engineering Applications of Artificial Intelligence 26: 779-788.

http://dx.doi.org/10.1016/j.engappai.2012.11.005

Wang, W. C.; Yu, W. D.; Yang, I. T.; Lin, C. C.; Lee, M. T.; Cheng, Y. Y. 2013. Applying the AHP to support the best-value contractor selection - lessons learned from two case studies in Taiwan, Journal of Civil Engineering and Management 19(1): 24-36. http://dx.doi.org/10.3846/13923730.2012.734851

Yager, R. 1981. A new methodology for ordinal multiobjective decisions based on fuzy sets, Decision Science 12: 589-600. http://dx.doi.org/10.1111/j.1540-5915.1981.tb00111.x 
Yu, D. J. 2013. Intuitionistic fuzzy prioritized operators and their application in multi-criteria group decision making, Technological and Economic Development of Economy 19(1): 1-21. http://dx.doi.org/10.3846/20294913.2012.762951

Zadeh, L. A. 1965. Fuzzy sets, Information and Control 8(3): 338-353. http://dx.doi.org/10.1016/S0019-9958(65)90241-X

Zadeh, L. A. 1973. Outline of a new approach to the analysis of complex systems and decision processes, IEEE Transactions on Systems, Man, and Cybernetics 3: 28-44. http://dx.doi.org/10.1109/TSMC.1973.5408575

Zavadskas, E. K.; Kaklauskas, A.; Vilutiene, T. 2009. Multicriteria evaluation of apartment blocks maintenance contractors: Lithuanian case study, International Journal of Strategic Property Management 13(4): 319-338. http://dx.doi.org/10.3846/1648-715X.2009.13.319-338

Zavadskas, E. K.; Turskis, Z.; Tamosaitiene, J. 2008. Contractor selection of construction in a competitive environment, Journal of Business Economics and Management 9(3): 181-187. http://dx.doi.org/10.3846/1611-1699.2008.9.181-187

Zavadskas, E. K.; Vilutiene, T.; Turskis, Z.; Tamosaitiene, J. 2010. Contractor selection for construction works by applying SAW-G and TOPSIS grey techniques, Journal of Business Economics and Management 11(1): 34-55. http://dx.doi.org/10.3846/jbem.2010.03.

Serdar ULUBEYLI is an Associate Professor of Construction Management Division in the Department of Civil Engineering at Bulent Ecevit University, Turkey. His areas of academic research interests include project management, subcontracting, and international construction projects. He has published many papers in various scientific journals and proceedings.

Aynur KAZAZ is an Professor of Construction Management Division in the Department of Civil Engineering at Akdeniz University, Turkey. Her areas of academic expertise include construction management, total quality management, and contract management. She is the author of many papers published in professional journals and conference proceedings. 